\title{
EXPLORING LI INTERFERENCE IN THE WRITINGS OF KADAZANDUSUN ESL STUDENTS
}

\author{
Chelster Sherralyn Jeoffrey Pudin \\ John Mark Storey \\ Loh Yoke Len \\ Suyansah Swanto \\ Wardatul Akmam Din \\ Center for the Promotion of Knowledge and Language Learning, \\ Universiti Malaysia Sabah, Malaysia \\ chelsterpudin@yahoo.com
}

First draft received: I 3 April 20 I5 Final draft received: 29 June 20 I5

\begin{abstract}
For many ethnic KadazanDusuns from Sabah, North Borneo, English is a third language after their mother tongue and Malay. The burden of having to contend with an additional language frequently leads to errors, particularly those caused by interference from the first language (L1). This study set out to identify the types and frequency of English language errors and their correlations in the writing of KadazanDusun ESL students at Universiti Malaysia Sabah. A further aim of the study was to establish which of these errors could be attributed to L1 interference. A total of 54 students with lower Malaysian University Entrance Test (MUET) band scores were asked to complete a questionnaire and write a short essay on a designated topic. The language errors were categorized and analysed via statistical analysis. Errors considered to be related to L1 interference were then identified after consultation with an experienced KadazanDusun language lecturer. The most common errors were those involving singular /plural nouns and unusual sentence structures. Approximately $25 \%$ of the errors were attributable to L1 interference, i.e. mode (normal/involuntary), voice (actor (-ing form) /undergoer (-ed form), overuse of article, linker (when linker is used, no article is needed), auxiliary verb and direct translation. The findings of this study give ESL practitioners a better insight into student errors and should lead to improved writing performance in the classroom.
\end{abstract}

Keywords: ESL writing, L1 interference, KadazanDusun

Learning a language can be a challenging experience for L2 learners. This is particularly so for Malaysian students whose English language learning has been affected by considerable changes in government education policy over the last 40 years. While the Third Malaysia Plan (Economic Planning Unit, Prime Minister's Department, 1976) pledged that English would still be taught as a strong second language (to ensure that Malaysia would not be left behind in terms of scientific and technological developments), Bahasa Melayu was the main medium of instruction in primary, secondary and tertiary level by the 1980s.

Inevitably, the declining role of English, led to deterioration in the standards of the spoken and written language, which the Malaysian government attempted to arrest with the restoration of English as the medium of instruction for science and mathematics at primary and secondary level in 2003. However, the policy was aborted in 2009. Consequently, the situation failed to improve. As an illustration, in 2012, Education Ministry Deputy Director-General, Datuk Dr Khair Mohamad Yusof stated that two in three Malaysian students had failed to meet the basics in English proficiency based on the comparison of the students' results in Sijil Pelajaran Malaysia (Malaysian Certificate of Education) English and Cambridge 1119 standards (Jalleh, 2012).
The net result of this decline in English language competence is a rise in the number of unemployed graduates, who are unable to secure jobs due to their lack of competence in the English language, particularly during interviews (Chan \& Helen, 2006:309). The Malaysian government is apparently addressing this issue by reassessing the standard of in-service English language teachers and by trying to improve the quality of language content delivery (Ministry of Education, Malaysia, 2013). One way educators can improve the effectiveness of their teaching is through error research.

Errors may frequently occur in the writing of English as a Second Language (ESL) learners. This is not surprising as writing has long been considered the most difficult of the four language skills due to the high demands of production, in terms of lexis, syntax, and semantics. Errors are caused by lack of knowledge about the target language, and are distinguishable from mistakes, which are caused by a lapse in language performance (Ellis, 1997). Typically, writing errors tend to be grammatical and involve the use of articles, verb tense, prepositions, subject-verb agreement; and syntactic, involving word order.

The study of these errors is of particular interest to teachers and linguists, who wish to identify them and the reasons for their occurrence. Corder (1967) states that 
analyzing learner errors enables researchers to know more about the processes involved in both teaching and learning. Furthermore, error analysis enables linguists working in the field of Second Language Acquisition (SLA) to discover more about the role played by errors in the developmental process of learning another language. From the results of such research, language professionals can create new syllabuses and materials, and adapt existing ones to ensure better learning outcomes for their students. Feedback on errors given to students empowers them and enables them to make strides towards achieving the desired language goals.

Interference occurs when learners utilize the structures of their first language (L1) when trying to communicate in the target language (Dulay \& Burt, 1974). It is reasonable to assume that the amount of L1 interference depends on the structural similarity between L1 and the second or target language (L2). The closer they are in terms of cognates and grammatical systems, the easier it will be for the students to learn the target language, whereas the less similar they are, the higher the likelihood of interference and errors (Lado, 1957, cited in Ellis, 2006:174).

Another factor influencing the amount of interference is the level of acquisition. Students who are less knowledgeable about the target language are forced to use existing L1 knowledge to fill in the gaps, resulting in a higher incidence of errors. Brown (1994a, 1994b) and White (2003) concluded that L2 beginners make more inter-lingual errors (due to L1 interference), whereas more intra-lingual errors (due to L2 interference) are noted as they become more proficient. Other factors contributing to interference include teaching and learning methods, the competency of the teacher, and differences in the cultures associated with the native and target languages.

Although English may officially be Malaysia's second language, it is certainly not true for all. A case in point is that of the Dusun people of North Borneo. The Kadazans and the Dusuns, traditional lowland rice farmers from the west coast of Sabah, comprise the largest single language community in the state accounting for $24 \%$ of the population (2010 Census Dept. of statistics, Malaysia). They speak a standardized form of their language, KadazanDusun, which comprises a number of dialects understood by all (Lasimbang, n.d.). After Independence and integration with Malaya in 1963, the emphasis was placed on the adoption of the Malay language, and once code-switching began to be practiced in Dusun households, the KadazanDusun language became increasingly marginalized.

The consequence of this is that Malay is now typically the second language (L2) of the KadazanDusun speaking community, while English is relegated to a third language (Lasimbang, n.d.). Having more than one language to contend with can create problems for ESL learners. Knowledge of the first language is often applied incorrectly to the target language, leading to errors and confusion over meaning. This scenario is quite likely in the case of the KadazanDusun ESL learners, who have at least 2 or 3 languages at their disposal.

Relatively little research has examined the errors made by KadazanDusun ESL learners and equally little is known about the impact of the mother tongue on their written English. Identifying and analyzing the source of these errors should enable teachers to tailor education programmes and teaching materials so that they address the specific needs of KadazanDusun ESL learners.

The aim of this research is to identify the type and frequency of English language errors and their significant correlations in the writing of KadazanDusun ESL learners at Universiti Malaysia Sabah, and the type and frequency of English language errors in the writing of KadazanDusun ESL learners which may be attributed to first language (L1) interference. In order to achieve the aims of the research, the following objectives were established: (1) to identify the most frequently occurring errors in the writing of KadazanDusun ESL learners at Universiti Malaysia Sabah, (2) to determine if there are any significant correlations between type and frequency of errors in the writings of KadazanDusun ESL learners, and (3) to investigate the errors that may be attributed to L1 interference.

There can be a vast difference between English written by native speakers (NS) and English written by English as a Second Language (ESL) learners. ESL learners have more than one language at their disposal while they are composing as compared to NS. Since they have more than one language in hand, it brings more problems. ESL learners tend to switch those languages interactively, resulting in some confusion in the sentence structure and meaning. Analysis and classification of the cause of confusion enable learners to have a clearer view of their problems and thus, able to produce better written texts. In the past, the focus of attention in L2 writing research has been mainly on the similarities between L1 and L2 writing processes despite the "salient and important differences" between them (Silva, 1993).

As several studies have reported, L2 writers use their L1 to plan their writing for text generation (Cumming, 1989; Jones \& Tetroe, 1987), transfer their L1 knowledge to L2 writing contexts (Edelsky, 1982; Friedlander, 1990; Lay, 1982) by developing ideas and producing text content and organization (Lay, 1982). In short, L2 writers always make use of their L1 first, while composing in the L2 before translating it to L2. This shows that L1 influences the L2 writers in their process of writing in L2 and the influences can be positive or negative.

Errors in language learners' performance, including writing process, have long become the subject of interest among teachers, linguists, and syllabus planners. The linguists particularly are interested in finding reasonable explanations for occurrence of errors and their implications towards the learning and teaching of a language. Corder (1967) mentions that there are two schools of thought with respect to learners' errors. The first school maintains that the occurrence of errors is merely a sign of present inadequacy of teaching techniques. The second school says that we live in an 
imperfect world and consequently errors will occur in spite of our best effort. According to Corder (1967), error can be defined as a systematic, consistent deviance characteristic of the learner's linguistic system at a given stage of learning.

Brown (1994a, 1994b) and Connor (1996) group errors into two categories. They are those errors that result from L1 interference which are external, and those which result from interference from the L2 system itself. The first category is caused by inter-lingual transfer. Inter-lingual transfer errors are errors caused by the interference of the learners' L1. Brown (1994a, 1994b) states that especially in the early stages of learning a L2, before the system of the L2 is familiar; the L1 is the only previous linguistic system upon which the learner can draw. The error occurs as a result of familiarity with the L1. Therefore, there is a transfer effect whether directly or indirectly of the L1 to the new language. When parallel features of the two languages correspond exactly, there is a positive transfer from L1 to L2. When they do not correspond exactly, there is a negative transfer, that is, interference (Ho, 1986).

Intra-lingual and developmental errors are the second category of errors. These errors may be caused by inadequate learning, difficulties inherent in the target language itself, faulty teaching, confused thinking or lack of contrast of both languages (Ho, 1986). Brown (1994a, 1994b) cites research suggesting that the early stages of language learning are characterized by a predominance of inter-lingual transfer, but once learners have begun to acquire parts of a new system, more and more intralingual transfer is manifested.

\section{METHOD}

This research examined relationships between the observable L1-induced errors and English essay writing. In addition, this exploratory effort sought to identify significant correlations, if any, between the various types of errors made. In an attempt to discover new information and new relationships to yet unresolved and unexplored questions as in this exploratory research, both qualitative data and quantitative scores are acceptable (Hair et al., 2007; Malhotra, 2007; Zikmund \& Babin, 2007). Therefore, this study adopted a quantitative research method. Quantitative methods are research techniques that are used to gather statistical information and measurable variables (Nunan, 2010:87-92), which are known as quantitative data. Statistics, tables, and graphs are often used to present results of these methods. Quantitative research is therefore measurable and quantifiable. Richards and Schmidt (2002: 436) describe quantitative research as any research that uses procedures that gather data in numerical form; more broadly, the term usually implies an approach to research that aims at causal explanation of phenomena through the identification of variables which can be made on the basis of experimental investigation. Since the present study is a contrastive study of errors in the English writing of learners, a quantitative method was considered appropriate for this research.

The remaining sections of this chapter describe details on the approach and procedures in conducting the current research. To begin with, the rational for selection of subjects is deliberated. Then, instruments utilised for the research are described. Next, the research data, data collection procedure, and data analysis are explained. Finally, a flowchart is provided as a summary of the research procedures.

\section{Subjects}

The subjects were purposively selected based on three criteria. These are their level of English language proficiency; the English language course they took at the Centre for the Promotion of Knowledge and Language Learning, University Malaysia Sabah; and their mother tongue or first language. Firstly, the level of English language proficiency was determined by the MUET (Malaysian University English Test) results obtained by the subjects. Since the purpose of the research is to identity errors made by students with low proficiency in English, selected subjects possess MUET Band 2 which indicates limited ability to function in the language. Students with MUET Band 1 were not selected as their very limited command of the language may hinder them from fulfilling the task. On the other hand, students with MUET Band 3 to 6 do not take the required course because they are considered as more proficient English language users.

Secondly, subjects had taken UB00302 Reading and Writing in English, which is the crucial course related to the research. In this course, subjects were taught how to write five-paragraph essays. Therefore, they have the schematic knowledge that is necessary for them to be able to fulfill the task set for them in this research. Thirdly, the first language or mother tongue of these subjects is KadazanDusun since this is the language of a major ethnic group in Sabah. This criterion limited the number of subjects to 78 . However, only 54 students participated in the research. There were 30 female and 24 male participants from the School of Arts and the School of Business and Economics.

\section{Instruments}

The research involved designing two instruments: a questionnaire for subjects, and a set of instructions on writing a descriptive essay. Firstly, the questionnaire was designed to obtain subjects' demographic details and certain linguistic information. This information includes L1 and L2 of subjects and their proficiency in Kadazan and Dusun languages. Secondly, the subjects were instructed to write a 5-paragraph essay about 'My Favourite Festival' in a minimum of 200 words in order to obtain sufficient data for analysing the errors made by them. The topic on subjects' festivals was selected because this culture-bound title is familiar to the subjects. There were no alternative titles given to ensure uniformity of contents. In addition, the subjects were guided by a set of six questions related to the topic. Furthermore, they have the prior knowledge on how to 
write descriptive essays during the 'Reading and Writing in English' course. Hence, subjects were given an appropriate writing task for their level of English language proficiency.

\section{Data}

The data comprised subjects' demographic details, and essays written by subjects. Firstly, responses to the questionnaire provide evidence that subjects meet the three criteria, qualifying them as participants of the research. Secondly, the essays of about 250-300 words serve as authentic texts for identification of errors made by the subjects when writing in English.

\section{Data collection procedure}

The data collection procedure began with identifying the potential subjects, followed by issuing them the invitation letter for participation in the research, and finally, getting them to fill in a questionnaire, and to write an essay entitled 'My favourite festival'. Initially, the chief researcher sent an email to all language instructors teaching UB00702 English for Occupational Purposes to identify whether there were any target students in their classes. Then, each researcher was assigned several classes which the target students were in and distributed the invitation letter of participation to them. The researchers briefed the subjects about the research and made appointments with them to write their essays. They were given three different time slots outside their class time to choose from.

When the subjects attended the writing session, they were instructed by the researchers to write a 5-paragraph essay about 'My Favourite Festival' in a minimum of 200 words. They wrote their essays under the supervision of the researcher in a classroom environment. They were not allowed to refer to any form of dictionary. There was no time limit given so that they could concentrate on producing a 5-paragraph essay, which forms the corpus of the current study. The subjects managed to finish the task within one and a half to two hours. Upon completion, they submitted their essays to the researcher supervising them.

\section{Data analysis}

Data analysis was conducted in three stages, namely identifying all the errors made by the students in their essays, conducting a consultation session with a specialist informant, and performing a statistical analysis of the errors identified using SPSS. During the first stage, researches identified all the errors by examining the essays. These errors were later classified into grammatical categories, namely syntax (e.g. word order), and grammatical structures (e.g. tenses or verb forms, subject-verb agreement, and others).

This was followed by the process of determining specific errors that show evidence of being influenced by L1. A consultation session was arranged with a specialist informant who is proficient in both English Language and KadazanDusun. She holds a first degree in English Language Studies (ESL) and a second degree in Linguistics. She is currently teaching KadazanDusun at the Centre of the Promotion of Knowledge and Language Learning, UMS. Upon examining the errors extracted from subjects' essays, she pointed out specific errors which are influenced by subjects' L1. In addition, she provided linguistic explanations based on the grammatical system of L1 for the occurrences of errors identified. The insight into L1 provided by the informant assisted in identifying the types and causes of errors which may be due to L1 transfer.

Finally, the statistical analysis commenced with coding of errors identified upon entering the data in SPSS. The grammatical errors were analysed according to the type of sample. Descriptive statistics of frequency was selected to ascertain the ranking of errors from the most common to the least. The category with the highest percentage was identified as the most frequent error made by the subjects. Furthermore, the association between L1 related errors and English essay writing was examined using descriptive statistics and correlative analysis in SPSS. The statistical technique used to measure the association and potential relationships between these variables included correlation analysis (Harnett \& Horrell, 1998; Lind, Marchal, \& Wathen, 2010).

Overall, the approach in conducting the research includes collecting samples of essays, identifying errors, describing, and explaining them. The findings were interpreted in the light of L1 negative transfer theory in relation to Contrastive Analysis, Error Analysis, and Interlanguage Analysis. The research commenced in June 2012 and was completed in June 2014.

This research focuses on exploring relationships between the observable mother tongue induced errors and English essay writing. This exploratory research attempts to find out significant correlations, if any, between the various types of errors made. Statistical techniques were used to measure the association and potential relationships between these variables, which will include correlation analyses (Harnett \& Horrell, 1998; Lind, Marchal, \& Wathen, 2010). In this regard, this study explores the relationship between writers' mother tongue and specific errors made.

The association between mother tongue related errors and English essay writing can be determined through descriptive statistics, reliability analysis and correlative analysis. Many of the research instruments used in social science research are summated scales. Reliability analysis measures the consistency of the research instrument to give reliable results by computing Cronbach's alpha. The reliability of a measure indicates the stability and consistency of the research instrument in measuring a concept and aids to assess the goodness of a measure (Sekaran, 2000). Cronbach's alpha is the coefficient of reliability, commonly used as a measure of the internal consistency or reliability of a psychometric test score. Cronbach's alpha will generally increase, as the inter-correlations among the test items are maximized, when all items measure the same construct.

Cronbach's alpha determines the internal consistency or average correlation of items in a survey instrument to gauge its reliability. A commonly accepted 
Table 1. Suggested guidelines for correlation coefficient

\begin{tabular}{lrr}
\hline \multicolumn{1}{c}{ Correlation } & Negative & \multicolumn{1}{c}{ Positive } \\
\hline None & -0.09 to 0.0 & 0.0 to 0.09 \\
Small & -0.3 to -0.1 & 0.1 to 0.3 \\
Medium & -0.5 to -0.3 & 0.3 to 0.50 \\
Strong & -1.0 to -0.5 & .5 to 1.0 \\
\hline
\end{tabular}

rule of thumb for describing internal consistency using Cronbach's alpha is given in Table 1. In the present study, reliability coefficient for the research instruments used in the study has been included in Table 4.2. The Cronbach's alpha for the data is 0.76 .

$$
\begin{array}{ll}
\alpha=.90 & \text { Excellent } \\
.90=\alpha=.80 & \text { Good } \\
.80=\alpha=.70 & \text { Aceceptable } \\
.70=\alpha=.60 & \text { Questionable } \\
.60=\alpha=.90 & \text { Poor } \\
\alpha<.50 & \text { Unacceptable }
\end{array}
$$

Research studies have applied correlative analysis to measure the strength and direction of the relationship between two constructs. To determine whether a significant association exists among demographic variables, organizational citizenship behaviour, and emotional intelligence correlations have been calculated. Pearson correlation matrix in Table 2 provides this information, as it describes the direction, strength, and significance of the association of the variables in the study (Sekaran, 2000). Many authors have suggested guidelines for the interpretation of a correlation coefficient.

The Pearson product-moment correlation coefficient (typically denoted by $r$ ), ranging between -1 and 1 , measures the degree to which two variables are linearly related. It is widely used in social sciences as a measure of the strength of linear dependence between two variables. The interpretation of a correlation coefficient depends on the context and purposes. A correlation of 0.9 which may be very low, if one is verifying a physical law using highquality instruments, but may be regarded as very high in social sciences where there it may have a greater contribution from complicating factors. The next table lists the suggested guidelines related to the quantum of correlation coefficient.

\section{RESULTS AND DISCUSSION \\ Mean Values}

The mean values for all constructs range between 0.056 and 3.482. The former refers to factors that had the

Table 2: Correlation coefficient results

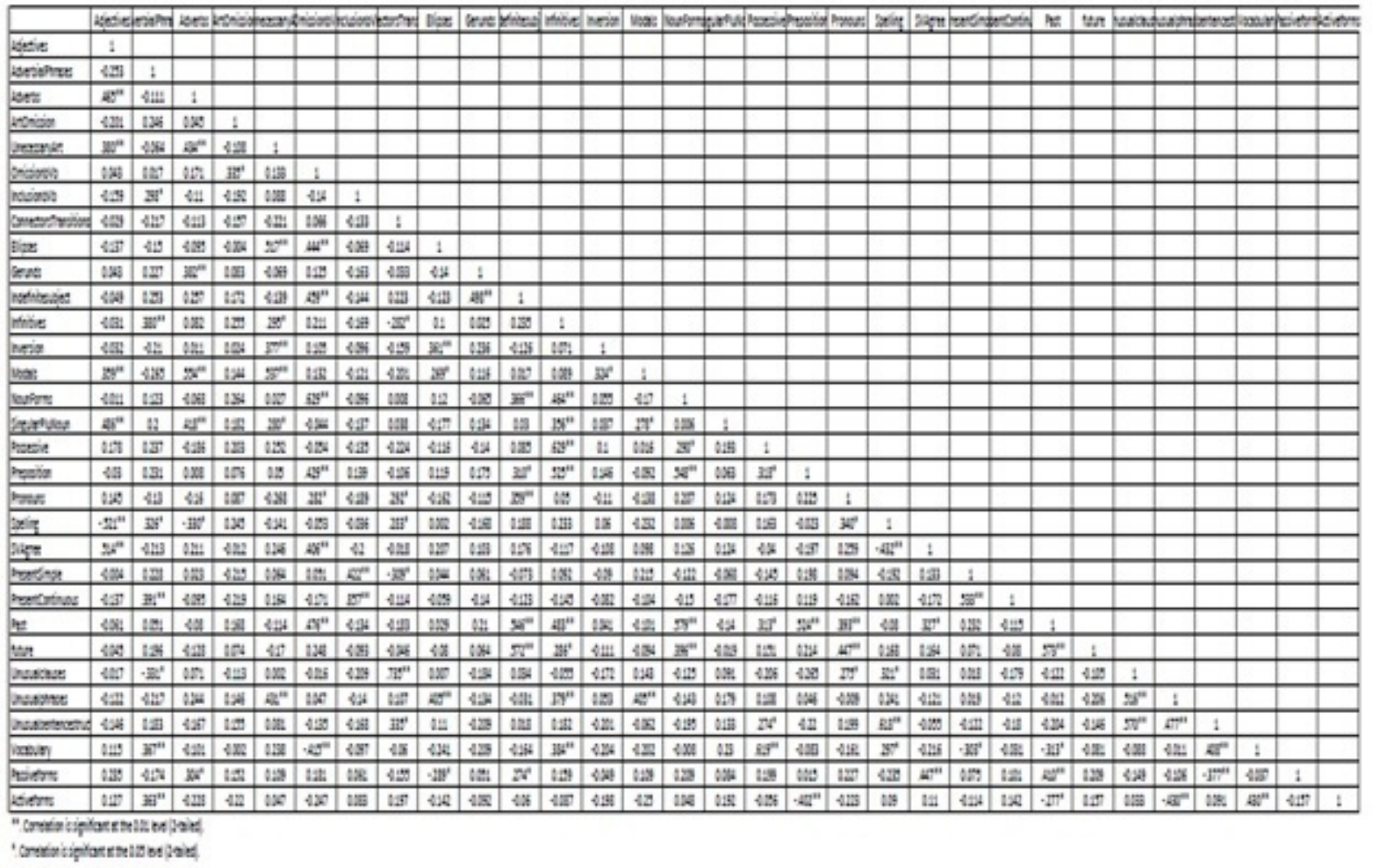


weakest mean values such as Ellipses and Present Continuous (mean=0.056), while the latter refers to factors like Singular/Plural Noun and Unusual sentence structures that had the highest mean value on a five-point Likert scale.

In other words, the mean for each variable allows us to decide the rank of the different variables as shown in Table 4.4. We can conclude that this group of students produce mostly errors in singular-plural nouns and unusual sentence structures followed by present simple, vocabulary, prepositions, spelling, and subject-verb agreement.

\section{Correlation}

Pearson correlation is executed to measure the intercorrelations between constructs. Correlation coefficients can range from the value of -1.00 to +1.00 (Lind, Marchal $\&$ Wathen, 2011). The value of -1.00 represents a perfect negative correlation, whereas a value of +1.00 represents a perfect positive correlation. In a positive correlation, as the value of one of the variables increases, the value of the second variable also increases. Likewise, as the value of one of the variables decreases, the value of the other variable also decreases. For example, income and education have a positive correlation. This implies that people with higher incomes tend to have more years of education while people with fewer years of education tend to have lower income. However, the reverse is true in a negative correlation. As the value of one of the variables increases, the value of the second variable decreases. Likewise, as the value of one of the variables decreases, the value of the other variable increases.

Table 3 reveals that many of the associations are positively correlated at $p<0.05$. Results portray that Adjectives have significant correlation at $p<0.01$ with six factors like Spelling $(r=-0.521)$, SVAgree $(r=0.514)$, SingularPluNoun $(r=0.486)$, Adverbs $(r=0.465)$, UnecessaryArt $(r=0.380)$, and Modals $(r=0.359)$, respectively. In other words, students who produce adjective mother tongue induced errors tend to produce errors in spelling, subject-verb agreement, singularplural nouns, adverbs, unnecessary articles, and modals.

Next, correlations with AdverbialPhrases are positively significant at $p<0.05$ among seven vital factors with correlation coefficients ranging between -0.331 and 0.391 , that is Unusualclauses $(r=-0.331)$, InclusionbVb $(r=0.298)$, Spelling $(r=0.326)$, Activeforms $\quad(r=0.363)$, Vocabulary $(r=0.367)$, Infinitives $(r=0.380)$, and PresentContinuous $(r=0.391)$, respectively.

In addition, Adverbs is positively significant at $\mathrm{p}<0.01$ among four vital factors with correlation coefficients ranging between 0.382 and 0.554 , that is UnecessaryArt $\quad(\mathrm{r}=0.434)$, Gerunds $(\mathrm{r}=0.382)$, Modals $(\mathrm{r}=0.554)$, and SingularPluralNoun $(\mathrm{r}=0.418)$. The next

Table 3. Mean values of errors made

\begin{tabular}{rlc}
\hline Rank & \multicolumn{1}{c}{ Variables } & Means \\
\hline 1 & Singular/plural noun & 3.482 \\
2 & Unusual sentence structure & 3.482 \\
3 & Present simple & 2.556 \\
4 & Vocabulary & 2.296 \\
5 & Preposition & 2.167 \\
6 & Spelling & 1.982 \\
7 & S-V Agreement & 1.907 \\
8 & Unusual phrases & 1.685 \\
9 & Passive forms & 1.482 \\
10 & Article omission & 1.019 \\
11 & Unusual clauses & 0.963 \\
12 & Omission of verb & 0.833 \\
13 & Past tense & 0.796 \\
14 & Pronouns & 0.778 \\
15 & Infinitives & 0.593 \\
16 & Noun forms & 0.556 \\
17 & Unnecessary articles & 0.537 \\
18 & Active forms & 0.500 \\
19 & Gerunds & 0.407 \\
20 & Adverbs & 0.370 \\
21 & Indefinite subjects & 0.370 \\
22 & Adverbial phrases & 0.278 \\
23 & Modal & 0.278 \\
24 & Connector/transitions & 0.259 \\
25 & Adjectives & 0.240 \\
26 & Future & 0.204 \\
27 & Inversion & 0.185 \\
28 & Possessive & 0.185 \\
29 & Inclusive verb & 0.074 \\
30 & Ellipsis & 0.056 \\
31 & Present continuous & 0.056 \\
& &
\end{tabular}


variable, ArticleOmission, did not seem to have any correlations.

On the contrary, results for 'Unnecessary article' show that the associations are positively correlated at $\mathrm{p}<0.01$ with four factors, namely Ellipses $(\mathrm{r}=0.517)$, Inversion $(\mathrm{r}=0.377), \quad$ Modals $(\mathrm{r}=0.377)$, and Unusual phrases $(\mathrm{r}=0.431)$.

Next 'Verb Omission', is positively significant at $\mathrm{p}<0.01$ among seven vital factors with correlation coefficients ranging between 0.406 and 0.629 , that is Ellipses $(r=0.444)$, Indefinitesubject $(r=0.459)$, NounForms $(r=0.629)$, Preposition $(r=0.429)$, SVAgreement $(\mathrm{r}=0.406)$, Past $(\mathrm{r}=0.476)$, and Vocabulary $(\mathrm{r}=-0.415)$.

'Verb inclusion' only produces two factors with coefficients of 0.422 (Present Simple) and 0.857 (Present Continuous). As for 'Connectors Transitions', it seems to correlate with 'Unusual clauses' with the coefficient of 0.735 . All of these prove to be positively significant at $\mathrm{p}<0.01$.

Furthermore, Ellipses correlates with Inversion ( $\mathrm{r}=$ $0.361)$, Unusual Phrases ( $\mathrm{r}=0.405)$, and Passive forms $(\mathrm{r}=0.405)$. All of them again prove to be positively significant at $\mathrm{p}<0.01$.

'Gerund' also proves to be positively significant at $\mathrm{p}<0.01$, but only shows positive correlation with

Table 4. Examples according to Error Types

\begin{tabular}{|c|c|}
\hline Errors attributed by L1 & Examples \\
\hline Mode (normal/involuntary) & ... when our festival coming \\
\hline $\begin{array}{l}\text { Voice (actor (-ing form)/ } \\
\text { undergoer (-ed form) }\end{array}$ & $\begin{array}{l}\text { Every year the festival will be celebrate (u) in Dusun community. } \\
\ldots \text { the famous festival will celebrated }(\mathrm{u}) \text { is ... } \\
\text { by used traditional things (undergoer) } \\
\ldots \text { is celebrate the festival with family. (actor) } \\
\text { Every year the festival will be celebrate (u) in Dusun community. } \\
\text { We just praying (a) to God ... } \\
\text { All of them come and show up and gathering (a) together ... } \\
\text { Before we dance, we was doing (a) a little exercise } \\
\text { Christmas celebration was fall (u) on... } \\
\text { After all done, we then visiting (a) each others home member of muslims... }\end{array}$ \\
\hline Overuse of article & $\begin{array}{l}\ldots \text { there have a other festival ... } \\
\text { but there is have a our own favourite festival } \\
\text { It is made by a paddy that become a rice. } \\
\ldots \text { the Word of the God. }\end{array}$ \\
\hline $\begin{array}{l}\text { Linker (when linker is used, } \\
\text { no article is needed) }\end{array}$ & $\begin{array}{l}\text { I'm (linker - no article) Kadazan dusun people. } \\
\text { Name of festival is ... (Linker) } \\
\text { several activities which is (complex linker - di or } d o \text { ) represented and illustrated Kadazan } \\
\text { / Dusun lifestyle ... }\end{array}$ \\
\hline Auxiliary verb & $\begin{array}{l}\text { As we know in Malaysia, there is have so many festival celebrated every year, since we } \\
\text { are have Indian, Chinese, Malay, Sabah and Sarawak indigeneous }\end{array}$ \\
\hline Direct translation & $\begin{array}{l}\text { why Christmas is (nopo nga) festival that I love the most. } \\
\text { on December every year (ontok - only one time prep) }\end{array}$ \\
\hline Sentence structure & $\begin{array}{l}\text { on December every year (ontok - only one time prep) } \\
\text { why Christmas is (nopo nga) festival that I love the most. }\end{array}$ \\
\hline $\begin{array}{l}\text { No emphasis on the usage of } \\
\text { plural forms }\end{array}$ & $\begin{array}{l}\text { Every years } \\
\text { The biggest cultures }\end{array}$ \\
\hline
\end{tabular}

'Indefinite subject' ( $\mathrm{r}=0.498)$. However, 'Indefinite Subject' is positively significant at $\mathrm{p}<0.01$ among four vital factors with correlation coefficients ranging between 0.382 and 0.554 .

Moreover, 'Infinitive' is positively significant at $\mathrm{p}<0.01$ among seven vital factors with correlation coefficients ranging between 0.356 and 0.629 , that is
'Noun Form'( $\mathrm{r}=0.396)$, 'Singular Plural Noun' $(\mathrm{r}=0.356)$, 'Possessive' ( $\mathrm{r}=0.629)$, 'Preposition' $(\mathrm{r}=0.525)$, 'Past'(r=0.483), 'Unusual Phrases' ( $\mathrm{r}=0.379)$, and Vocabulary $(\mathrm{r}=0.384)$.

However, no coefficient is detected for 'Inversion' and 'Singular Plural Noun'. On the contrary, 'Modal' seems to correlate with 'Unusual Phrases' $(r=.405)$. 
'Noun Form' on the other hand, is positively significant at $\mathrm{p}<0.01$ among three vital factors with correlation coefficients ranging between 0.382 and 0.554 , that is Preposition $(\mathrm{r}=0.548)$, Past $(\mathrm{r}=0.579)$, and future $(\mathrm{r}=0.396)$.

Further assessment of the correlation coefficients revealed that the following types of errors are the major concern of the students' in regards to its association with the dimension of SingularPluNoun: Adjectives $(r=0.486)$, Adverbs $(r=0.418)$, Infinitives $(r=0.356)$, respectively followed by UnecessaryArt $(r=0.280)$ and Modals $(r=0.278)$. The correlation between

Unusual sentencestructures is highly significant and positively linked with factors such as Spelling $(r=0.618$, $p<0.05)$, followed by Unusualclauses $(r=0.570, p<0.05)$, and Unusualphrases $(r=0.477, p<0.05)$. Besides, students need to pay careful attention to ConnectorsTransitions $(r=0.335, p<0.05)$, and Possessive $(r=0.274, p<0.05)$

\section{Common errors attributed to $\mathrm{L} 1$ interference}

There are eight common errors found which were apparently influenced by L1. The errors detected were classified in terms of mode (normal/involuntary), voice (actor (-ing form) /undergoer (-ed form)), overuse of article, linker, auxiliary verb, vocabulary/ direct translation, sentence structure, and zero emphasis on the usage of plural forms.

\section{CONCLUSION}

In conclusion, some transfer effect was evident in the students' essays. In other words, it is likely that the students' L1 has some influence on their English writing, resulting in the errors found. Negative transfer appeared to be more significant than positive transfer in the students' essays. A total of 31 grammatical errors were detected and 8 of these were identified as being probably influenced by the learners' L1. As indicated on page 21, the most frequently occurring errors made by KadazanDusun ESL learners were those with the highest mean Likert values, such as those involving singular / plural nouns and unusual sentence structures, while those with the lowest mean values, such as ellipses and present continuous, were the least frequently occurring.

In terms of correlations in the writings of the learners, mother tongue-induced adjective errors typically include errors in spelling, subject-verb agreement, singularplural nouns, adverbs, unnecessary articles and modals. Adverbs correlated with errors featuring unnecessary articles, gerunds, modals and singular / plural nouns. While article omissions did not produce any correlations, the use of unnecessary articles was found to be associated with errors involving ellipses, inversion, modals and unusual phrases. Verb omission correlated with errors featuring ellipses, indefinite subject, noun forms, prepositions, subject-verb agreement, past tense and vocabulary, whereas verb omission had fewer correlations (present simple and present continuous errors only). Connector transitions correlated with unusual clauses, while ellipses correlated with inversion errors, unusual phrases, and mistakes involving passive forms. Gerunds had a positive correlation with indefinite subject errors. In contrast, infinitive errors were associated with errors involving noun form, singular / plural nouns, possessives, prepositions, past tense, unusual phrases, and vocabulary. Although no coefficient was detected for inversion and singular / plural nouns, modals seemed to correlate with unusual phrases. Noun form errors formed positive correlations with prepositions, past tense, and future tense.

The errors which may possibly be attributable to L1 interference include those associated with singular / plural nouns: adjectives, adverbs and infinitives have the strongest associations respectively, while. unnecessary articles and modals are also linked. Unusual sentence structures are also a potential indicator of L1 interference, and manifest themselves in the form of spelling errors, unusual clauses, and unusual phrases.

\section{Limitations}

- The limitations that are identified throughout conducting this study are as follows:

- No previous research is available to allow comparison.

- Concentrating only on Bands 1 and 2 seems to be limiting in terms of data gathered.

- Another language is involved and the interference from this language has not taken into account.

- The available sample size is rather small so the result cannot be generalized for the whole population.

\section{Recommendations for future research}

Since further research is necessary to provide concrete evidence and conclusive findings, the current research acts as a leap pad for more challenging and interesting research in the future. A variety of related research can be conducted by modifying essay title, language skills, proficiency level of subjects, and ethnic groups, as well as distinguishing the influence of L1 and L2 on learning the third language.

Firstly, students can be given different titles to choose for their writing. It would be interesting to find out if the type of error made by students is determined by the contents of their writing. Another perspective to investigate is identifying errors made by subjects when speaking instead of writing. A further extension of this research would be to compare and contrast the errors made in speech and in writing.

It is also recommended that a more comprehensive study involving KadazanDusun students from all MUET Bands be conducted to examine the relationship between subjects' proficiency level and the type of error made.

Next, investigation and comparison of L1 interference on the English writing of other ethnic groups including KadazanDusun can be conducted by examining errors made by different ethnic groups in Sabah, such as Rungus, Bajau, and Murut. This type of research may lead to the identification of errors that could be specific to a particular ethnic group. Since students 
from different ethnic groups in Sabah speak more than two languages, such as KadazanDusun (L1), Malay (L2), and English (L3), future research can also focus on the extent of negative transfer of L1 and L2 in learning L3.

It is hoped that the future research recommended can encourage better collaboration between linguists and practitioners in identification of errors and reduction or even elimination of negative transfer of L1 and L 2 among ESL learners. In addition, findings from proposed research will provide insight into second language learning and even third language acquisition.

\section{REFERENCES}

Arnett, D.L. \& Horrell, J. F. (1998). Data, statistics, and decision models. New York, NY: Wiley

Brown, H. D. (1994a). Teaching by principles: An interactive approach to language pedagogy. Englewood Cliffs, New Jersey: Prentice Hall Regents.

Brown, H.D. (1994b). Principles of language and teaching $\left(3^{\text {rd }}\right.$ ed.). Englewood Cliffs, New Jersey: Prentice Hall.

Chan, S. H., \& Helen, T. (2006). English for mathematics and science: current Malaysian language-in-education policies and practices. Language and Education, 20(4), pp. 306-321.

Chan, S. H., \& Wong, B. E. (2004). Assessing oral skills of pre-tertiary students: The nature of the communicative act. Paper presented at the International Conference on English Instruction and Assessment.

Connor, U. (1996). Contrastive rhetoric: cross-cultural aspects of second-language writing. Cambridge: Cambridge University Press.

Corder, S. P. (1967). The significance of learners' errors. International Review of Applied Linguistics, 5, pp. 161-9.

Cumming, A. (1989). Writing expertise and second language proficiency. Language Learning, 39, pp. 81-141.

Department of Statistics, Malaysia (2010). Population and housing census, Malaysia 2010. Retrieved on 27 May, 2014 from www.statistics.gov.my

Dulay, H. C. \& Burt, M.K. (1974). Errors and strategies in child second language acquisition. TESOL Quarterly, 8(2), pp. 129-136.

Economic Planning Unit, Prime Minister's Department (1976). Third Malaysia plan, 1976-1980. Retrieved June 10, 2014 from: www.epu.gov.my/en/third-malaysia-plan-19761980

Edelsky, C. (1982). Writing in a bilingual program: The relation of L1 and L2 texts. TESOL Quarterly, 16, pp. 211-228.

Ellis, N. C. (2006). Selective attention and transfer phenomena in L2 acquisition: contingency, cue competition, salience, interference, overshadowing, blocking, and perceptual learning.
Applied Linguistics, 27(2), pp. 164-194.

Ellis, R. (1997). Second language acquisition. Oxford: Oxford University Press.

Friedlander, A. (1990). Composing in English: Effects of a first language on writing in English as a second language. In B. Kroll (Ed.), Second language writing: Research insights for the classroom (pp. 109-125). Cambridge University Press, New York.

Hair, J. F. (Jr.), Black, W. C., Babin, B. J., \& Anderson, R. E. (2007). Multivariate Data Analysis (7th Ed.). USA: Pearson Higher Education

Harnett, D. L., \& Horrell, J. F. (1998). Data, statistics, and decision models. New York: Wiley.

Ho, D. (1986). Two contrasting positions on second language acquisition: a proposed solution. International Review of Applied Linguistics, 24, pp. 35-47.

Jalleh, J. (2012, Sept. 26). Majority of teachers not proficient in English. The Star Online. Retrieved June 20, 2014 from www.thestar.com.my/news/Nation/2012/09/26/Ma jority-of-teachers-not-proficient-in-English/

Jones, C. S. \& Tetroe, J. (1987). Composing a second language. In A. Matcuhashi (Ed.), Writing in real time: Modelling the production processes (pp. 3457). Norwood, New Jersey: ABLEX.

Lasimbang, R. (n.d.). Introduction. KadazanDusun Language Foundation. Retrieved June 12, 2014 fromwww.klf.com.my/index $2 . h$ tm

Lay, N. D. (1982). Composing processes of adult ESL learners: A case study. TESOL Quarterly, 16, 406407.

Lind, D.A., Marchal, W.G., \& Wathen, S.A. (2011). Basic statistics for business \& economics (11th ed). New York, USA: McGraw-Hill.

Malhotra, N. K. (2007). Review of marketing research. Vol. 3. Pennsylvania: M. E. Sharpe.

Ministry of Education, Malaysia. (2013). Malaysian education blueprint (2013-2025). Putrajaya: Kementerian Pendidikan Malaysia.

Nunan, D. (2010). Research methods in language learning. Cambridge: Cambridge University Press

Richards, J. C., \& Schmidt, R. (2002). Longman dictionary of language teaching \& applied linguistics (3rd ed.). Oxon, UK: Pearson.

Sekaran, U. (2000). Research method for business: A skill-building approach. Third Ed. New York: John Wiley \& Sons, Inc.

Silva, T. (1993). Toward an understanding of the distinct nature of L2 writing: The ESL research and its implications. TESOL Quarterly, 27, pp. 657-677.

White, L. (2003). Second language acquisition and Universal Grammar. Cambridge: Cambridge University Press.

Zikmund, W. G., \& Babin, B. J. (2007). Essentials of marketing research (3rd ed.). Mason, Ohio: Thomson/South-Western Place. 